ISSN: 2162-3104 Print/ ISSN: 2166-3750 Online

Volume 8, Issue 3 (2018), pp. 1386-1397

(C) Journal of International Students

http://jistudents.org/

doi: 10.5281/zenodo.1254599

\title{
Leveraging Common Ground: Improving International and Domestic Students' Interaction Through Mutual Engagement
}

\author{
Victor F. Thomas \\ Simon Fraser University, Canada \\ Joseph M. Ssendikaddiwa \\ Simon Fraser University, Canada \\ Martin Mroz \\ Simon Fraser University, Canada \\ Karen Lockyer \\ Simon Fraser University, Canada \\ Karin Kosarzova \\ Simon Fraser University, Canada \\ Carolyn Hanna \\ Simon Fraser University, Canada
}

\begin{abstract}
Leading institutional pedagogies and practices tend to approach increasing international student populations from a deficit-based model, which focuses on the adaptation, acculturation, and assimilation of international students to the dominant host culture. We believe a better approach to improve international and domestic students' interaction is to move to models of mutual engagement. In this article, as practitioners, we explore four common grounds that seem to be producing positive engagements: common experience, cultural celebrations, faith, and common challenges, in which students are encouraged to meaningfully engage with each other as equals in a spirit of mutuality. The resulting discussion explores how each
\end{abstract}


contributes to a culture of collaboration within institutional departments while improving and enriching the interactions between all students.

Keywords: collaboration, common grounds, cross-cultural learning, engagement, mutuality

International student numbers are projected to grow from five million (ICEF Monitor, 2015) to over seven million globally by 2025 (Bohm, Davis, Meares, \& Pearce, 2002). Canada, in particular, saw a major surge in foreign students in 2016 with a 17.5\% increase (ICEF Monitor, 2017). While campuses are increasingly international, research from within Canada (Canadian Bureau for International Education [CBIE], 2015) and beyond (e.g., Leask, 2009; Lee \& Rice, 2007) shows that the "integration challenge" is real (CBIE, 2015). International and domestic students struggle to engage with each other and develop meaningful connections. An approach that seems to be improving mutual interaction is leveraging common grounds, such as common experiences, faith, cultural celebrations, and common challenges.

\section{LITERATURE REVIEW}

Dominant institutional pedagogies and practices tend to view international student populations from a deficit-based model. This model focuses on the adaptation, acculturation, and assimilation of international students to the dominant host culture (Hechanova-Alampay, Beehr, Christansen, \& Van Horn, 2002; Klineberg \& Hull, 1979; Sandhu \& Asarabi, 1994).

The deficit-based model assumes that international students need to change in some way to realize positive relationships with domestic students. Despite research and efforts aimed at helping international students acculturate, assimilate, and adapt so they can thrive and build cross-cultural connections with domestic students, there is still a significant disconnect (CBIE, 2015; Thomson \& Esses, 2016). In fact, a research brief by CBIE (2015) suggests that current approaches have been unsuccessful in helping international and domestic students connect. A 2014 Canadian national survey by CBIE found that the majority of international students (54\%) have no domestic friends (CBIE, 2015). Additionally, 1 in 3 international students (37\%) found it difficult to get to know domestic students in Canada. Zhang and Goodson's (2011) extensive review of 64 papers pointed out that this disconnect between domestic and international students is clearly associated with negative psychological outcomes for the latter. 
On the other hand, some studies have found that specific types of programs facilitate relationships between international and domestic students. For example, Gresham and Clayton (2011) found that through their structured Community Connections program, built around mutual engagement, they achieved significant positive impacts regarding relationship development. The program required all students to agree to interact frequently in common tasks, responsibilities, and activities. Similarly, Thomson and Esses (2016) found that creating intentional environments in the context of a mentorship relationship had positive outcomes on relationship development between international and domestic students. Volet and Ang (1998) highlighted that the "mixing gap" between international and domestic students exists because too little attention is given to developing two-way relationships. Underscoring this, the literature is clear that when relationships are formed between international and domestic students, there are numerous positive sociological outcomes for all involved (Hechanova-Alampay et al., 2002; Ying \& Han, 2006).

There seems to be an acute need for better approaches to improving international and domestic student relationships. Rose-Redwood and RoseRedwood (2013) suggest that "programs would be more effective if they abandoned the assimilationist doctrine of adjustment to the dominant culture and instead promoted the programmatic goal of mutual engagement" (p. 426). Thus, we advocate for using common grounds to build mutual engagement to facilitate supportive and favorable learning environments in which all parties can thrive.

\section{COMMON GROUNDS}

Simon Fraser University (SFU) has continued to experiment with progressive and practical approaches that move away from simply categorizing students by visa status. SFU is rather choosing to leverage common grounds to meaningfully engage all students in topics, issues, or activities of mutual interest. Real friendships are built as each person brings their real self to the common ground.

In this practitioner narrative, we aim to share and discuss four common grounds: common experience, cultural celebrations, faith, and shared challenges. At SFU, these have been successful at producing mutual engagement, cultivating cross-cultural learning, and developing international friendships. 


\section{Common Experience}

Shared experiences have proved to be a valuable common ground. One initiative that has brought international and domestic students together in meaningful ways has been the Community Cooking Workshops. This is a project within SFU's Healthy Campus Community initiative and a partnership between the Health Promotion team, International Services for Students, and Residence and Housing.

International and domestic students work in small teams to prepare and enjoy a healthy meal together while learning about nutrition and gaining food preparation skills. The common experience encourages conversation and builds social connection while promoting feelings of belonging and mutual engagement. These types of supportive environments have been found to have major positive impacts in initiating social connections among students of different backgrounds (National Survey of Student Engagement [NSSE], 2015). This is further supported by Rose-Redwood and RoseRedwood's (2013) findings that "[ $t]$ he principle of mutual engagement encourages inclusive forms of global social mixing as the ideal type of social interaction, since this has the potential to foster meaningful crosscultural dialogue among different nationalities, including the host community" (p. 426). The table below shows results of 124 international and domestic student evaluations of 10 Community Cooking Workshops between 2016 and 2017.

Table 1. Community cooking workshop outcomes for 2016-2017.

\begin{tabular}{ll}
\hline Percentage & Outcome \\
\hline $85 \%$ & Reported making a new friend. \\
$84 \%$ & $\begin{array}{l}\text { Reported that they were confident that they could incorporate } \\
\text { ideas/tips/strategies into their lives. }\end{array}$ \\
& $\begin{array}{l}\text { Reported that their knowledge/understanding about healthy } \\
\text { eating improved. }\end{array}$ \\
\hline
\end{tabular}

The workshops provide valuable spaces for mutual engagement and building social connectedness, as illustrated by the notably high percentage $(85 \%)$ of students reporting new friendships. Furthermore, student evaluations included comments such as, "My favorite part was socializing, playing games and cooking with other people," and "We need more events like this to gather people."

The cooking workshops create an intentional environment which helps transcend cultural and social barriers, fosters connections, and engages 
students in a spirit of mutuality. This results in enhancing both international and domestic student learning and personal connections.

\section{Cultural Celebrations}

SFU has experienced success leveraging cultural celebrations (e.g., lunar new year, Nowruz, Diwali, Gung Haggis Fat Choy) to enhance mutual interaction between international and domestic students. Another example is the annual Christmas Eve dinner held by the Interfaith Centre in partnership with International Services for Students. The dinner has proven to be a powerful way of bringing diverse individuals together so "no one dines alone" over the holiday season. Domestic students are intentionally encouraged to attend as a way for them to connect with international students during the season. The dinner involves food, Santa's arrival, and a competition between group tables to build the best gingerbread house.

Celebrations such as these create opportunities for discussion and the formation of relationships, helping to combat the sense of isolation that the holiday season can induce for students. At the best of times, loneliness is a major issue in North American universities, with the American College Health Association (2016) reporting that $66.6 \%$ of students surveyed felt "very lonely." The dinners have proven to engage students, help them combat loneliness, and enhance the opportunity for building new relationships.

In 2015 and 2016, 130 and 107 students, respectively, attended with minimal advertising. In 2016, a diverse group of students gathered for the celebration, with Iranians constituting $30 \%$ of participants, Chinese students making up $45 \%$, and the rest were a mix of various domestic and international backgrounds. Moreover, 35\% were graduate students, 50\% were undergraduate students, and $15 \%$ were a mix of alumni, staff, community members, and families.

By coming together in celebration, there has been an increase in engagement and conversations between students from different ethnic and religious backgrounds. Similar results have been noted at the annual Thanksgiving dinner hosted to bring together international and domestic students to celebrate this Canadian cultural celebration. The attendance and interest in this event has also grown over the years from 70 students in 2010 to 225 in 2017. After the 2017 Thanksgiving dinner, a domestic student commented: "I had an amazing time and it was fun hearing the different things that students from other countries were thankful for." These cultural celebrations appear to have provided opportunities for mutual engagement where domestic and international students can interact, connect, and build relationships. 


\section{Faith}

Employing faith as a common ground has shown signs of positive outcomes when it comes to mutual interaction and cross-cultural learning. Faith is a common ground for the majority of the world's population $(84 \%)$ and is projected to grow to $87 \%$ by 2050 (Pew Research Center, 2015). The ability to wisely leverage the common ground of faith creates a starting point for connections amongst a large percentage of international and domestic students. Kuh and Gonyea (2006) point out that "[s]tudents who engage frequently in spirituality-enhancing activities ... [tend to] exercise more, attend cultural events more often, and are more likely to perform community service. They also are somewhat more satisfied with college and view the out-of-class environment more positively" (p. 44). This is largely because they have a basis for connection with many others and can access networks of relationships. Kuh and Gonyea (2006) go on to argue that "[t]here is no evidence that spiritual practices have negative effects on other desirable activities, such as studying, deep learning, or extracurricular involvements" (p. 44).

Table 2. The number of students involved weekly at the SFU Burnaby interfaith centre at certain periods between 2007 and 2017 .

\begin{tabular}{|c|c|c|c|c|}
\hline Involved weekly & 2007 & $2011^{\mathrm{a}}$ & $2014^{\mathrm{a}}(\%)$ & $2017^{\mathrm{a}}(\%)$ \\
\hline Total weekly & 70 & 700 & 1256 & 1447 \\
\hline Internationals ${ }^{b}$ & & & $285(23 \%)$ & $494(34 \%)$ \\
\hline Domestic $^{c}$ & & & $971(77 \%)$ & $953(66 \%)$ \\
\hline Graduate students & & & $98(8 \%)$ & $158(11 \%)$ \\
\hline Faculty and staff & & & $58(5 \%)$ & $80(6 \%)$ \\
\hline Group leaders $^{\mathrm{d}}$ & & & $37(3 \%)$ & $52(4 \%)$ \\
\hline Weekly gatherings & & & 105 & 116 \\
\hline
\end{tabular}

${ }^{\text {a}}$ Total enrollment 2011: 29,718, 2014: 29,579, and 2017: 29,563; 'People who selfidentify as internationals; ${ }^{\circ}$ Calculated by total people less internationals; ${ }^{\mathrm{d}} \mathrm{Number}$ of chaplains and student leaders that facilitate groups.

The Interfaith Centre leads faith services at SFU, and the university has realized the potential of leveraging faith to respond to spiritual needs, reach recruitment goals, and increase connections between students. Since 2007, this has been attempted through incrementally aligning its practices with recommendations that Chickering, Dalton, and Stamm (2006) have proposed. Thus, faith has been recognized as an important aspect of holistic student wellbeing. Furthermore, SFU has significantly increased the size and number of spaces available for chaplains and students engaged in faithrelated activities. Finally, as recommended by Chickering, Dalton, and 
Stamm (2006), the centre's services are now widely publicized in a variety of ways, such as in recruitment material and as part of new student orientation for the university and student residences.

The impact of these changes over the past decade seems to have resulted in significant growth in the number of international and domestic students using faith services. The table below highlights the growth in weekly use for certain periods over the past decade.

Table 2 describes the significant growth in use of the faith services at SFU. Over the same period, the profile of faith services at SFU has been promoted, with the increasing of space and mainstreaming of faith services. The SFU Burnaby Interfaith Centre weekly engagement numbers have grown from 70 in 2001 to 1,447 in 2017. In 2014 and 2017, the number and percentage of those self-identifying as international students, grew from 285 $(23 \%)$ to $494(34 \%)$. The notable growth means a third of those involved in the 116 weekly gatherings and activities are international students.

The centre is a hive of activity with large numbers of international and domestic students from various faith backgrounds. The open space, participation of faculty, large student numbers, and diversity of international and domestic students helps create the context necessary, as described by NSSE (2015), for high impact engagement between diverse groups. This interaction provides opportunities for the development of cultural learning and friendships. A number of joint interfaith events (e.g., Non-Violence Day) along with incidental connections in the open lounge spaces has been observed to foster deep relationships between students of various faiths.

Student feedback of services further supports the survey data that the centre helps create a platform for the formation of diverse friendships. Two self-described international students commented: "I feel at home here" and "When I first arrived in Canada, I had no one, but here I found friends who helped me find food and even how to get library books." Furthermore, two domestic students commented, "We have a common bond of faith," and "The group of people I have met through interfaith are the people I study with."

Leveraging the common ground of faith has not only been advantageous in recruitment but more importantly serves as a starting point for students to build relationships. Our experiences, feedback received, and the results of surveys appear to indicate that leveraging faith facilitates the creation of mutual interactions that lead to the formation of new friendships and cultural learning. 


\section{Common Challenges}

While common experiences, celebrations, and faith can provide the impetus for mutual engagement, the all-too-common challenge of racism and discrimination can impact both international and domestic students and can threaten to create division and misunderstanding.

Following the issuance of the first Executive Order under the Trump Administration in 2017 (Petter, 2017a) and the violence at the Centre Culturel Islamique de Quebéc, Canada (Petter, 2017b), SFU mobilized in support of those affected and reaffirmed the institution's commitment to diversity, equity, and inclusion.

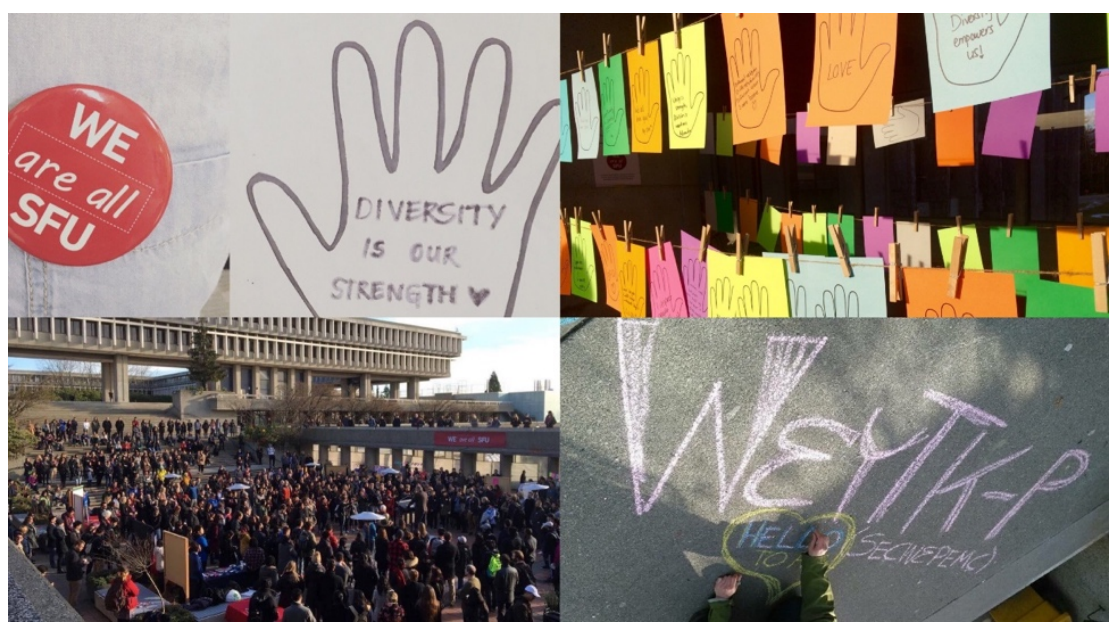

Figure 1. Pictures from the event showing the We are all SFU badge, notes of solidarity, and Indigenous "Welcomes" in traditional languages.

At the event entitled "We Are All SFU," approximately 1,300 domestic and international students, staff, and faculty gathered to participate in dialogue and show support for those facing discrimination, racism, and intolerance as a result of these discriminatory actions. SFU Indigenous community members arrived early to write welcome in their traditional languages as seen in Figure 1. Demonstrating solidarity, attendees wrote messages of support which were placed around the university. SFU's President encouraged attendees to build bridges instead of walls and highlighted the importance of creating an environment where every member feels supported and valued (Petter, 2017b).

The outpouring of support and level of mutual engagement shown during the event demonstrated that many community members felt 
impacted, either directly or indirectly. As the title suggests, the "We are all SFU" event was designed to dissipate the imagined boundaries between diverse student groups and stand in unity against discrimination, racism, and intolerance. Tinto (2017) identifies a sense of belonging as a pivotal factor for student persistence. In this case, the common challenge faced was racism and discrimination, but it became the basis for uniting a wide variety of domestic and international students.

In reflecting on the event, the Chair of the SFU-World University Service of Canada (WUSC) Local Committee spoke of the "great sense of comfort" that she felt when seeing the university come together as one and how grateful she was to be attending a university that is "boldly unafraid to make their stance on this subject matter clear." The president of the SFU Shia Muslim Society (SMS), an international student, wrote a letter of thanks expressing her "warmest gratitude" and how "deeply touched" the SMS group of "students, majority of which are Canadian-Iranian, CanadianIraqi and international students from Iran" were for the event. This common challenge brought a significant spectrum of students together in action and dialogue. What could easily have become divisive and polarizing, instead became reconciliatory, promoting cross-cultural learning, understanding of each other's faiths, and the development of friendship.

\section{CONCLUSIONS AND IMPLICATIONS}

The integration challenge is real and current deficit-based approaches are not yielding significant positive outcomes. SFU shifted to developing common grounds that attempt to mutually engage students and staff working inter-departmentally to achieve mutual engagement, cross-cultural learning, and developing international friendships.

There are many powerful opportunities for institutions to identify and implement common ground activities that have meaningful outcomes for the whole community. To be successful, these should be diverse in size, topic, and/or activity to promote inclusion and provide opportunity for students with different styles and preferences for engagement within their communities.

Further research would help build a solid base for best practices offering achievable opportunities to enhance integration and engagement between domestic and international students, while increasing collaboration of staff and faculty to benefit the whole community. 


\section{REFERENCES}

American College Health Association. (2016). American College Health Associationnational college health assessment II: Canadian reference group executive summary, Spring 2016. Hanover, MD: American College Health Association. Retrieved from: http://www.acha-ncha.org/

Association of Universities and Colleges of Canada. (2014). Canada's universities in the world: AUCC internationalization survey. Retrieved from Universities Canada website: http://www.aucc.ca/wp-content/uploads/ 2014/12/internationalization-survey-2014.pdf

Bohm, A., Davis, D., Meares, D., \& Pearce, D. (2002). Global student mobility 2025: Forecasts of the global demand for international higher education. Canberra, Australia: IDP Education Australia. Retrieved from: http://www.foresightfordevelopment.org/sobipro/55/333-global-studentmobility-2025-forecasts-of-the-global-demand-for-international-highereducation

Canadian Bureau for International Education (2015, June). The integration challenge: Connecting international students with their Canadian peers. Retrieved from Canadian Bureau for International Education website: https://cbie.ca/wpcontent/uploads/2016/04/CBIE-Research-in-Brief-2-The-IntegrationChallenge-EN.pdf

Chickering, A., Dalton, J.C., \& Stamm, L. (2006). Encouraging authenticity and spirituality in higher education. San Francisco, CA: Jossey-Bass

Gresham, R., \& Clayton, V. (2011). Community connections: A programme to enhance domestic and international students' educational experience. Journal of Higher Education Policy and Management, 33(4), 363-374.

Hechanova-Alampay, R., Beehr, T. A., Christiansen, N. D., \& Van Horn, R. K. (2002). Adjustment and strain among domestic and international student sojourners: A longitudinal study. School Psychology International, 23(4), 458-474.

ICEF Monitor. (2015, November 5). The state of international student mobility in 2015. Retrieved from http://monitor.icef.com/2015/11/the-state-of-internationalstudent-mobility-in-2015/

ICEF Monitor. (2017, Nov 22). Canada's international student enrolment surged in 2016. Retrieved from http://monitor.icef.com/2017/11/canadas-internationalstudent-enrolment-surged-2016/

Klineberg, O. \& Hull, W.F. (1979). At a foreign university: An international study of adaptation and coping. New York: Praeger Publishers Inc.

Kuh, G.D. \& Gonyea, R.M. (2006). Spirituality, liberal learning and college student engagement. Liberal Education, 92(1), 40-47. Retrieved from https://files.eric.ed.gov/fulltext/EJ743277.pdf

Leask, B. (2009). Using formal and informal curricula to improve interactions between home and international students. Journal of Studies in International Education. 13(2), 205-221.

Lee, J.R. \& Rice, C. (2007). Welcome to America? International student perceptions of discrimination. Higher Education, 53(3), 381-409.

National Survey of Student Engagement. (2015, July 23). Engagement indicators \& high-impact practices. Retrieved from National Survey of Student Engagement website: 
http://nsse.indiana.edu/pdf/EIs_and_HIPs_2015.pdf

Petter, A. (2017a, January 29). President's statement on U.S. travel ban [transcript]. Retrieved from http:/www.sfu.ca/pres/petterspeeches/2016/ president_s-statement-on-u-s--travel-ban.html

Petter, A. (2017b, February 2). President's speech at we are all SFU event [transcript]. Retrieved from: https://www.sfu.ca/pres/petterspeeches/2017/presidents-speech-we-are-all-sfuevent.html

Pew Research Center. (2015, April 2). The future of religions: population growth projections, 2010-2050. Retrieved from Pew Research Center website: http://assets.pewresearch.org/wpcontent/uploads/sites/11/2015/03/PF_15.04.02_ProjectionsFullReport.pdf

Rose-Redwood, C.R. \& Rose-Redwood, R.S. (2013). Self-segregation or global mixing? Social interactions and the international student experience. Journal of College Student Development, 54(4), 413-429.

Sandhu, D.S. \& Asarabi, B.R. (1994). Development of an acculturative stress scale for international students. Psychological Reports, 75, 435-448.

Thomson, C., \& Esses, V.M. (2016). Helping the transition: Mentorship to support international students in Canada. Journal of International Students, 6(4), 873886.

Tinto, V. (2017). Through the eyes of students. Journal of College Student Retention: Research, Theory and Practice, 19(3), 254-269.

Volet, S.E.\& Ang, G. (1998). Culturally mixed groups on international campuses: An opportunity for inter-cultural learning. Higher Education Research \& Development, 17(1), 5-23.

Ying, Y., \& Han, M. (2006). The contribution of personality, acculturative stressors, and social affiliation to adjustment: A longitudinal study of Taiwanese international students in the United States. International Journal of Intercultural Relations, 30(5), 623-635.

Zhang, J., \& Goodson, P. (2011). Predictors of international students' psychosocial adjustment to life in the United States: A systematic review. International Journal of Intercultural Relations, 35(2), 139-162.

VICTOR F THOMAS, MSc., is the Director \& Head Chaplain of the Interfaith Centre at Simon Fraser University. His mandate includes the oversight of the faith services, supports, spaces, and engagement on campus. His research interests include student wellbeing, faith \& religion on campus, food security, and sustainability. Email: vthomas@sfu.ca

JOSEPH M SSENDIKADDIWA, is an undergraduate student at Simon Fraser University in the Health Science Faculty. He is interested in health systems and public policy research as well as pedagogical paradigms. Email: jssendik@sfu.ca

MARTIN MROZ, MSc., CPA-CMA, is the Director of Health \& Counselling Services at Simon Fraser University. His mandate includes clinical health services, counselling services, health promotion, and mental health strategies, primarily with a focus on students. Email: martin_mroz@sfu.ca 
KAREN LOCKYER, MA, RCIC, is an International Student Advisor at Simon Fraser University. Her mandate includes the delivery of services and supports for students from international pathways. Email: klockyer@sfu.ca

KARIN KOSARZOVA, MEd, RCIC, is the Manager of International Student Advising and Programs team at Simon Fraser University. Her mandate includes delivery of services and supports for students from international pathways. Email: karin_kosarzova@sfu.ca

CAROLYN HANNA is the Director of International Services for Students at Simon Fraser University. Her mandate includes international learning abroad, intercultural student engagement programming, and services and supports for students from international pathways. Email: clong@sfu.ca 